\title{
Clinical Reasoning: A 22-year-old man presenting with headache and right leg jerks
}

Alexander J. Schupper, BA,* Kevin McGehrin, MD,* John Ravits, MD, and David Lee, MD, PhD

Neurology ${ }^{\circledR}$ 2018;91:891-895. doi:10.1212/WNL.0000000000006476

\section{Section 1}

A 22-year-old man with no pertinent medical history presented to our emergency department with headaches, nausea, vomiting, and right leg jerks. Two days prior, he developed a suddenonset, throbbing headache that was $6 / 10$ in severity involving his entire head. He denied photophobia/phonophobia or visual changes. He felt dizzy and lightheaded without room spinning. The next day, he noticed his right leg felt "heavy." That evening, he had nausea and 2 episodes of emesis. The next morning, he awoke with insuppressible "twitches" in his entire right leg. These were not painful and occurred every few seconds at rest and with activity. No history of similar headaches, abnormal movements, trauma, seizures, sick contacts, or recent travel was noted. Family history was unremarkable. He had normal development, completed high school, and worked full-time installing solar panels.

Upon examination, the patient was afebrile, alert, in no acute distress, and without nuchal rigidity. Funduscopic examination revealed no papilledema. Mental status and cranial nerve examinations were normal. Motor examination revealed normal bulk and tone, with 4/5 strength throughout his right leg. Right leg jerks were seen every $1-4$ seconds at rest and during spontaneous movements (video 1). These were insuppressible, voluntarily or with tactile stimulation, and did not worsen with startle. He had decreased sensation to light touch in his right leg up to his proximal thigh circumferentially; vibratory, temperature, and pinprick sensation was preserved. Bilateral deep tendon reflexes were normal with downgoing toes. He was ataxic on right finger-to-nose and heel-to-shin testing. Gait was not assessed due to his frequent right leg jerks.

\section{Questions for consideration:}

1. Where do you localize the patient's symptoms and clinical signs?

2. What do you include in your differential diagnosis?
Correspondence

Dr. Lee

dlee@ucsd.edu

MORE ONLINE

Video

GO TO SECTION 2

*These authors contributed equally to this work.

From the Department of Neurosciences, University of California San Diego, La Jolla.

Go to Neurology.org/N for full disclosures. Funding information and disclosures deemed relevant by the authors, if any, are provided at the end of the article. 


\section{Section 2}

The description of this patient's right leg movements is most consistent with myoclonus. Myoclonus is a sign consisting of brief, involuntary, jerk-like movements due to either muscle contraction (positive myoclonus) or inhibition (negative myoclonus). Based on localization, myoclonus can be separated into the following categories: cortical, subcortical, spinal, and peripheral. ${ }^{1}$

1. Cortical myoclonus is the most common type and is caused by lesions interfering with electrical activity within the cerebral cortex. It often presents with positive and negative myoclonus and can be triggered by sensory stimuli or muscle activation. Simultaneous EEG and EMG shows a focal, time-locked cortical transient abnormality that precedes the myoclonus by a short latency. ${ }^{2}$ When confined to one part of the body and lasting hours to weeks, it is referred to as epilepsia partialis continua (EPC). Cortical myoclonus can be a component of epilepsy syndromes such as infantile spasms, juvenile myoclonic epilepsy, and Rasmussen encephalitis.

2. Subcortical myoclonus is caused by lesions affecting subcortical and brainstem structures. It is characterized by excessive reciprocal excitation of diffuse, bilateral cortical and subcortical sites and is often accompanied by generalized seizures. ${ }^{2}$ Electrophysiologic characteristics are variable, but EEG will often show spike or polyspike discharges. This category includes hyperekplexia and opsoclonus-myoclonus syndrome.

3. Spinal myoclonus is caused by lesions affecting the spinal cord such as syringomyelia, myelitis, trauma, or malignancy.
It is characterized by brief and involuntary segmental or propriospinal muscle contractions that are often responsive to narcotics and antiepileptic medications. ${ }^{2}$ A startle response is often present.

4. Peripheral myoclonus is characterized by rhythmic or semirhythmic jerks secondary to lesions affecting a plexus, nerve, or nerve root. A common example is hemifacial spasm.

Our patient's clinical presentation is most suggestive of cortical myoclonus. His motor and sensory findings suggest a lesion involving his left frontal and parietal lobes. His normal cranial nerve examination and absent startle response decrease the likelihood of subcortical myoclonus. The history and examination does not suggest plexus or nerve root pathology. His symmetric reflexes and lack of startle response decrease the likelihood of spinal and peripheral myoclonus.

Once the diagnosis of cortical myoclonus has been established, the differential diagnosis remains broad. The abrupt onset, new headache, nausea, and vomiting are concerning for an infectious or inflammatory encephalitis. Another diagnosis to consider is cerebral venous thrombosis, as patients often present with new-onset headaches and $44 \%$ present with newonset seizures. ${ }^{3}$ Neoplastic and paraneoplastic etiologies should also be considered in all patients presenting with cortical myoclonus in the absence of epilepsy history.

\section{Questions for consideration:}

1. What investigations would you perform next?

2. How would you manage this patient?

\section{GO TO SECTION 3}




\section{Section 3}

The patient was admitted for further management. Video EEG and EMG revealed repetitive, sharply contoured theta-delta potentials over his vertex and left central regions, which were temporally associated with his right leg jerks (video 2). MRI brain revealed a T2/fluid-attenuated inversion recovery hyperintensity involving his left cingulate gyrus, medial left temporo-occipital lobe, and left parietal lobe with patchy contrast enhancement (figure, A, D, and G). Magnetic resonance angiography/magnetic resonance venography brain revealed no evidence of vascular abnormality or venous thrombosis. Lumbar puncture revealed a white blood cell (WBC) count of $170 / \mathrm{mm}^{3}$ and red blood cell (RBC) count of $4,200 / \mathrm{mm}^{3}$ in tube 1 and a WBC count of $120 / \mathrm{mm}^{3}$ in tube 4 (67\% neutrophils) and RBC count of $675 / \mathrm{mm}^{3}$ in tube 4 , protein $44 \mathrm{mg} / \mathrm{dL}$, and glucose $67 \mathrm{mg} / \mathrm{dL}$. Bacterial, fungal, and viral CSF cultures were negative. NMDA receptor antibodies and paraneoplastic workup were negative. A broad viral infectious workup was negative, including evaluation for herpes simplex virus (HSV), West Nile virus, Epstein-Barr virus, cytomegalovirus, and arboviruses. Cytology showed no atypical cells.

The patient was treated with lorazepam $2 \mathrm{mg}$ IV twice without improvement. He was then started on valproic acid, levetiracetam, and IV acyclovir. His myoclonic jerks did not change with these interventions.

\section{Questions for consideration:}

1. What is the most likely diagnosis?

2. How would you manage this patient? 


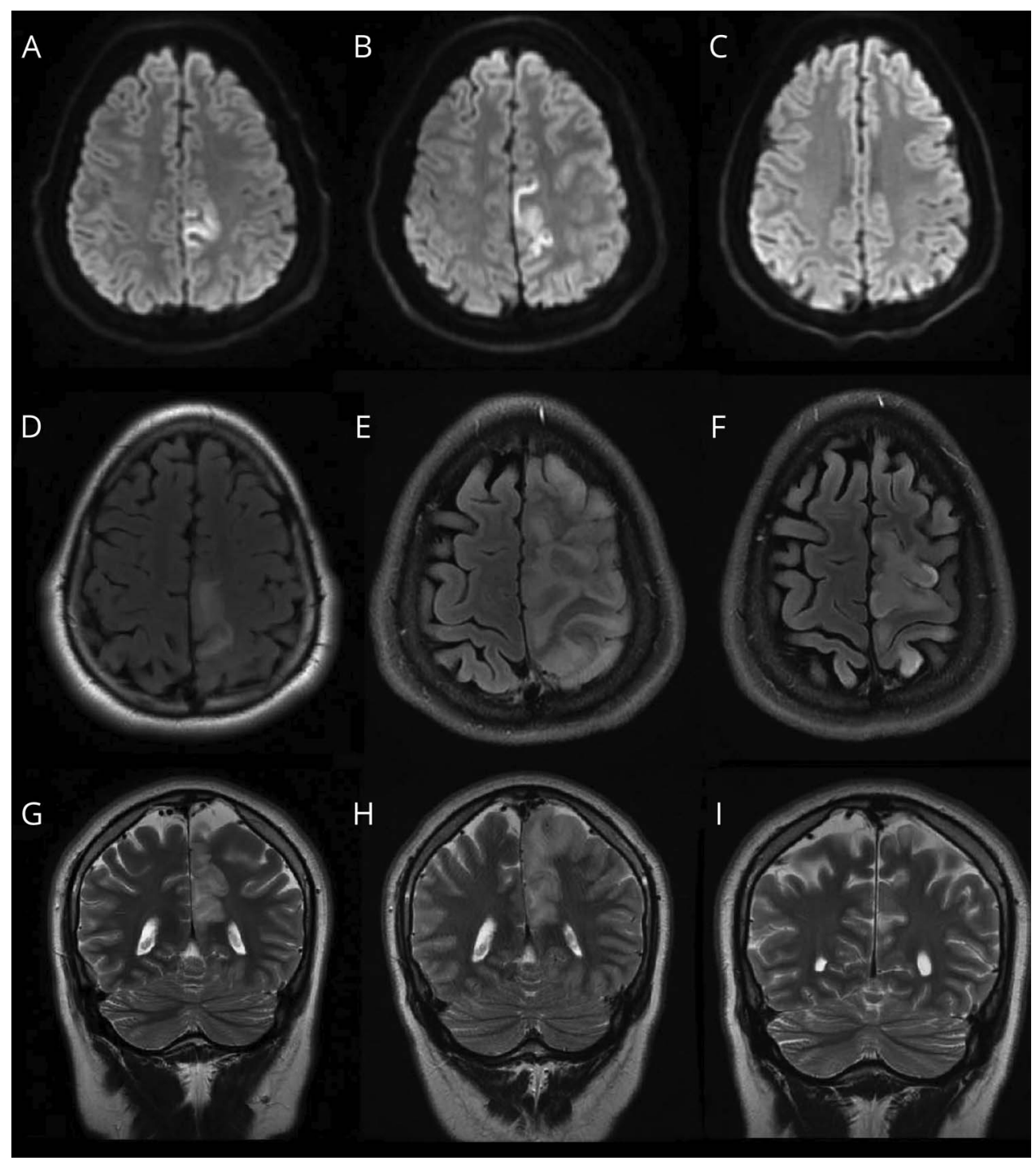

Axial diffusion-weighted imaging on hospital day $1(\mathrm{~A})$, hospital day $4(\mathrm{~B})$, and 1 month postdischarge (C). Axial T2/fluid-attenuated inversion recovery on hospital day 1 (D), hospital day 4 (E), and 1 month postdischarge (F). Corona T2 on hospital day 1 (G), hospital day 4 $(\mathrm{H})$, and 1 month postdischarge (I). 


\section{Section 4}

This patient's overall clinical picture is most consistent with cortical myoclonus progressing to EPC. His focal, time-locked EEG abnormalities and myoclonic jerks are consistent with cortical myoclonus. Given that his myoclonus is confined to one part of his body and has been lasting for hours to days, he meets criteria for EPC. A focal viral encephalitis as the cause of his EPC is supported by his time course of symptoms, MRI brain findings, and neutrophil-predominant pleocytosis. A specific viral pathogen was not identified, but up to $60 \%$ of encephalitis cases remain undiagnosed. ${ }^{4}$

On hospital day 3, the patient developed weakness and myoclonic jerks of his right arm. Repeat EEG showed multiple focal seizures localized to his left centroparietal region. Oxcarbazepine was added without effect. On hospital day 4, his clinical condition deteriorated, with new somnolence, right facial droop, dysarthria, and flaccid right arm and leg weakness. Repeat brain MRI showed increased left-hemispheric gyriform cortical diffusion restriction with new involvement of his right frontal lobe (figure, B, E, and $\mathrm{H}$ ). He was started on a 5-day course of methylprednisolone $1 \mathrm{~g}$ IV daily, transferred to the neurocritical care unit, and his antiepileptic medications were increased.

By hospital day 5, the patient's seizures stopped and his focal weakness began to improve. Acyclovir was discontinued after HSV PCR resulted negative. He ambulated with a walker by hospital day 7 and was discharged on day 10 to a rehabilitation facility. By discharge, he had residual weakness (4/5) and sensory loss of the right leg, which persisted at a 4-week follow-up visit. Repeat MRI brain 1 month after admission showed decreased edema and evolution of the left-sided cortical diffusion restriction (figure, C, F, and I). He remained seizure-free on antiepileptic medications.

\section{Discussion}

EPC is a form of simple focal motor status epilepticus that is sustained for an extended period. It was named by Kojewnikoff in 1894 in describing a prolonged focal seizure, and later defined by Obeso et al. ${ }^{5}$ in 1985 as "spontaneous regular or irregular clonic muscle twitching of cerebral cortical origin, confined to one part of the body and continuing for a period of hours, days, or even weeks." Consciousness is initially preserved, but there may later be altered awareness and secondary generalization.

EPC is a rare seizure disorder, with the largest case series including 76 patients. ${ }^{6}$ This series found that patients were typically young, with a mean age of 30.2 years, and the majority (69\%) manifested EPC with no prior seizure history.
Almost all patients had abnormal MRI and EEG studies. Most patients required multiple antiepileptic medications, and a majority of patients (59.7\%) eventually attained seizure control. Etiologies are varied, with inflammatory, infectious, vascular, traumatic, and mass-related etiologies being most common.

EPC is typically drug-resistant, with $84 \%$ of patients requiring 2 or more antiepileptic medications. ${ }^{6}$ In comparison to convulsive status epilepticus, the goal of EPC is to contain generalization and prevent sedation, as the harm associated with deep sedation or intubation presumably has a higher risk profile than the neuronal injury associated with EPC. The optimal treatment for EPC has not been well-established as there have been no randomized studies. Historically, phenytoin has been the most commonly utilized initial treatment. However, recent studies suggest that valproate may be more efficacious. ${ }^{7}$ Other antiepileptic agents shown to be effective include levetiracetam and lacosamide.,

Overall, the prognosis is primarily dependent on quickly identifying and treating the underlying etiology. In adults with EPC, approximately $40 \%$ of patients have medically refractory seizures and $4 \%$ of cases are fatal despite antiepileptic therapy. ${ }^{6}$ Given its morbidity and mortality, early identification and antiepileptic therapy is critical in the treatment of EPC.

\section{Author contributions}

A.J. Schupper: manuscript concept and initial draft. K. McGehrin: manuscript concept and initial draft, creation of video. J. Ravits: revision of manuscript for intellectual content. D. Lee: revision of manuscript for intellectual content, creation of video.

\section{Study funding}

No targeted funding reported.

\section{Disclosure}

The authors report no disclosures relevant to the manuscript. Go to Neurology.org/N for full disclosures.

\section{References}

1. Kojovic M, Cordivari C, Bhatia K. Myoclonic disorders: a practical approach for diagnosis and treatment. Ther Adv Neurol Disord 2011;4:47-62.

2. Caviness JN. Treatment of myoclonus. Neurotherapeutics 2014;11:188-200.

3. Masuhr F, Busch M, Amberger N, et al. Risk and predictors of early epileptic seizures in acute cerebral venous and sinus thrombosis. Eur J Neurol 2006;13:852-856.

4. Kennedy PGE, Quan PL, Lipkin WI. Viral encephalitis of unknown cause: current perspective and recent advances. Viruses 2017;9:E138.

5. Obeso JA, Rothwell JC, Marsden CD. The spectrum of cortical myoclonus: from focal reflex jerks to spontaneous motor epilepsy. Brain 1985;108:193-224.

6. Sinha S, Satishchandra P. Epilepsia partialis continua over last 14 years: experience from a tertiary care center from south India. Epilepsy Res 2007;74:55-59.

7. Yasiry Z, Shorvon SD. The relative effectiveness of five antiepileptic drugs in treatment of benzodiazepine-resistant convulsive status epilepticus: a meta-analysis of published studies. Seizure 2014;23:167-174.

8. Alvarez V, Januel JM, Burnand B, Rossetti AO. Second-line status epilepticus treatment: comparison of phenytoin, valproate, and levetiracetam. Epilepsia 2011;52:1292-1296.

9. Höfler J, Trinka E. Lacosamide as a new treatment option in status epilepticus. Epilepsia 2013;54:393-404. 


\section{Neurology}

\section{Clinical Reasoning: A 22-year-old man presenting with headache and right leg jerks}

Alexander J. Schupper, Kevin McGehrin, John Ravits, et al. Neurology 2018;91;891-895

DOI 10.1212/WNL.0000000000006476

\section{This information is current as of November 5, 2018}

Updated Information \& Services

References

Subspecialty Collections

Permissions \& Licensing

Reprints including high resolution figures, can be found at: http://n.neurology.org/content/91/19/891.full

This article cites 9 articles, 0 of which you can access for free at: http://n.neurology.org/content/91/19/891.full\#ref-list-1

This article, along with others on similar topics, appears in the following collection(s):

Encephalitis

http://n.neurology.org/cgi/collection/encephalitis

Epilepsy monitoring

http://n.neurology.org/cgi/collection/epilepsy_monitoring_ Myoclonus

http://n.neurology.org/cgi/collection/myoclonus

Video/ EEG use in epilepsy

http://n.neurology.org/cgi/collection/video_eeg_use_in_epilepsy

Information about reproducing this article in parts (figures,tables) or in its entirety can be found online at:

http://www.neurology.org/about/about_the_journal\#permissions

Information about ordering reprints can be found online:

http://n.neurology.org/subscribers/advertise

Neurology ${ }^{\circledR}$ is the official journal of the American Academy of Neurology. Published continuously since 1951, it is now a weekly with 48 issues per year. Copyright (C) 2018 American Academy of Neurology. All rights reserved. Print ISSN: 0028-3878. Online ISSN: 1526-632X.

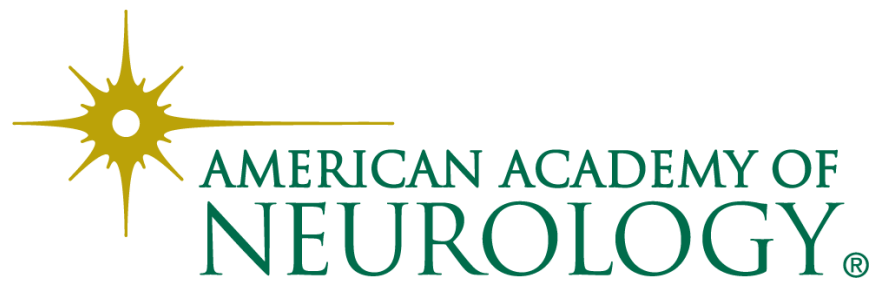

